\title{
Using critical realism and reflexivity to explain broadband non-adoption in rural Australia
}

\author{
Philip Dobson \\ Centre for Innovative Practice \\ School of Business \& Law \\ Edith Cowan University \\ p.dobson@ecu.edu.au \\ Paul Jackson \\ Centre for Innovative Practice \\ School of Business \& Law \\ Edith Cowan University
}

\section{Abstract}

Australia is conducting a substantial nationwide provision of broadband. It is primarily a fixed line network but includes wireless and satellite networks in more remote areas. The rollout is under the control of the NBN Co, whose goal is ensuring access to fast broadband for all Australians. The NBN Co has recently recognized the importance of adoption by including premises activated as a KPI alongside service provision. Coverage and adoption reflect the two faces of the NBN rollout - as a technical program and as a social program. Adoption will be the ultimate measure of the success of the NBN as a social program. Ubiquitous Internet adoption across all sectors is necessary to maximize the promised benefits. The adoption of broadband is an important first step in achieving this. International experience suggests that broadband adoption is plateauing and this has prompted our proposal that there needs to be focus on nonadoption rather than adoption. We suggest that it is important to be able to explain the mechanisms by which individuals respond to the promise of the Internet. Only by so doing can we address issues. We contend that there needs to be more focus on those disenchanted or disinterested "non-users" who are never likely to adopt without specific targeted strategies. We argue for a critical realist perspective, more particularly reflexivity, to better represent the adoption context and to provide a grounding for explanations of the causes behind the decision not to adopt. We also propose possible common-sense strategies to reverse non-adoption.

Keywords: Broadband adoption, social realism, modes of reflexivity, Technology Acceptance Model

\section{Introduction}

Announced as a key policy by the Labor Party prior to the 2007 election in Australia, the National Broadband Network (NBN) is being implemented across Australia. Whilst it is mainly a fixed line network using mixed copper and optical technology with Fibre to the Node, wireless and satellite networks are also used to supply services to remote areas. Whilst being an instrument of industrial policy which will facilitate production and consumption, the original motivation also embodied a substantial equity motive, connecting those in sparsely populated remote and less affluent regions which would otherwise not be economically viable to connect (Cave and Martin, 2010). The NBN Co was founded in 2009 to manage the rollout. Their objective is to deliver broadband to all Australians.

The benefits of such a service are acknowledged, with many countries worldwide recognizing broadband service or internet service as a legal right, human right or citizen's right (Broadband Commission 2015). The principle of a universal service is that all users should be provided with a range of basic but good quality services at affordable prices. The national Australian telecommunications operator Telstra has had a universal services obligation (USO) with respect to telephony provision for many years and more recently there has been a call to apply such a USO to broadband on completion of the current national rollout. This USO needs to 
focus on what is provided rather than how - the provision of Internet services can take many forms including fixed line, satellite, wifi and media not invented yet (Cradduck 2016).

A recognition of the benefits of universal provision, and perhaps a USO, is an important first step in achieving promised Internet benefits. However, it is important to distinguish between the provision of Internet services and the adoption/activation of such technologies. This has clearly been appreciated by the NBN Co in their acceptance of two key performance indicators - service provision (homes and businesses serviceable) and premises activated. It is suggested that activations are exceeding expectations with recent reports showing approximately 2.9 million premises made ready for service and 1.1 million activated (NBN Co, 2016).

Horrigan and Duggan (2015) examine the adoption of broadband in the home in the US and suggest that adoption levels are plateauing at around 70\%; this plateauing a consequence of the increasing adoption of mobile broadband. Perrin and Duggan (2015) more generally analyse Internet usage for American users over 2000-2015. They suggest that some sectors are reaching near saturation levels whilst other sectors are lagging. Lagging sectors include rural regions, the elderly, lower income households and African-Americans and Hispanics. We suggest that this plateauing is a consequence of a core of "non-adopters" rather than so called "laggards". We argue that in order to address non-adoption we need to focus on the characteristics of non-adopters and understand the individual motivations behind the decision not to adopt.

In this paper we focus particularly on rural adoption where despite strong promotion, reasonable pricing and social and economic benefits, adoption of broadband and its alternatives have been disappointing and well behind that of urban regions. LaRose et al (2007, p. 360) suggests the rural benefits of broadband are substantial including the fostering of social interactions to increase attachment to rural communities and reduce out-migration; enhancing economic opportunities by stimulating the development of home businesses; and improving rural access to health care and education. Using rural America as an example they suggest an important paradox in that the region most to benefit is lagging behind in adoption.

We suggest that the rollout of large-scale technology platforms, such as the NBN, need to be considered as importantly a social program as well as a technical program. This different focus requires a careful contextual examination of the social reality, or ontology, of agents both in terms of the context within which the adoption decision is made and in the way that agents consider this context in relation to their personal "projects" and their own particular ways of behaving. As Archer (2003) suggests, people always have the possibility to do otherwise than expected or predicted - this unexpected behaviour depends largely on their own reflexive deliberations - their "internal conversation". It is this reflexive engagement of purposive agents with their existing social contexts that needs to be understood in order to explain the reasons behind non-adoption.

Non-adoption is a significant barrier to achieving many of the benefits of ubiquity (such as access to many government services, particularly medical or educational). It is important that the non-adopters be better understood. We suggest that particular modes of reflexivity are associated with particular types of non-use and propose particular strategies for these different categories of non-use. We suggest that only by understanding the social reality of agents and their reflexivity (impacted by their natal, experiential and social history) can we hope to be able to explain and possibly address this rejection of broadband and its alternatives. We first examine some types of non -use and suggest that reflexivity is an important mechanism for explaining non-adoption. In particular, we suggest that two modes of reflexivity will explain much of the non-adoption (as described later in the paper these are the "communicative" and the "fractured"). We critique the dominant TAM based research models used to predict and evaluate adoption patterns, suggesting that the lack of a clear ontology for these models limits their application to the undoubted social complexity of Internet adoption and usage. We then suggest ways for promoting broadband targeted at particular reflexive modalities. We consider the context of rural adoption to better highlight our arguments. 


\section{Focusing on the non-user}

Satchell and Dourish (2009) describe a range of varieties of non-use including lagging adoption, active resistance, disenchantment, disenfranchisement, displacement and disinterest.

The concept of lagging adopters can be seen to be prevalent in much of the Internet adoption literature to date and in the statistics used to examine adoption. Much of the literature discusses the benefits of universal adoption and the desirability of improving the factors supporting adoption - they implicitly assume that $100 \%$ adoption is possible. Yet the adoption of broadband or its alternatives is ultimately a voluntary choice for many, home use being perhaps more voluntarist than business in that businesses, through competitive threats, might generally be expected to adopt the Internet promptly for commercial reasons.

Non-use is not all about laggards, active resistance is an option for some users in that they may actively reject the Internet for various reasons such as concern for privacy. Similarly disenchantment may be reflected by a limited or partial use of Internet applications as a reflection of nostalgic regret for things changing.

Disenfranchisement or exclusion can take many forms as Satchell and Dourish (2009, p. 12) suggest: "Interest in universal accessibility has largely focused on physical and cognitive impairments as sources of technological disenfranchisement, but it may also have its origins in economic, social, infrastructural, geographical, and other sources". The investigation of disenfranchisement depends heavily on an understanding of contextual social and personal situations and the particular material and ideational structures in place.

Similarly displacement is an important concept in that many "users" will depend on different material and social intermediaries to achieve their Internet connection. Family members may depend on "local experts" (Stewart 2007) to fulfil their Internet requirements. Such a variation of "non-use" is difficult to quantify, but by applying the notion of reflexivity, it can be explained by reference to the "communicative reflexive" who depends on "similars and familiars" to assist their daily obligations and desires. Such degrees of "non-use" are difficult to get a grip on when the dominant model for understanding adoption is considering a person with their own computer and not some public provision or private arrangement. The concept of "user" is challenged by such use or "non-use".

The final category of disinterest is perhaps the most difficult challenge for researchers and those promoting broadband in that the non-user may have no interest in the things that you assume they are interested in. As will be described below this is the domain of the "fractured" reflexive - those who are not participants in society but rather victims. Converting such a group is important since for many these persons have the most to gain, both economically and socially.

The crucial constraint in current adoption models is that they cannot properly represent these non-adopters nor make clear the causes behind the non-adoption. Such consideration often requires a careful deep analysis of the social and contextual: simple factors models cannot provide this depth. Much more sophisticated models are needed to reflect the complexity of adoption and non-adoption.

In particular current research models have no recognition of the different types of user and how their different life worlds affect the adoption decision. We suggest the consideration of reflexivity to better explain non-adoption.

\section{The role of reflexivity}

We propose a focus on non-adopters and suggest the importance of reflexivity as a mechanism to help explain the non-adoption decision. The characteristics of the potential adopter need to be considered, as well as the context. Potential users differ in their cultural and economic environments, personal characteristic, their capabilities and their life-concerns. As Kontos and 
Poland (2009) suggest when examining social health care improvements, there is a need to reflect human choice along with context in examining government programs:

In seeking to understand how mechanisms play out in a particular setting, with particular agents at a specific time, we must also take account of how reflexive agents perceive, negotiate, unwittingly reinforce or selectively resist the effects of these broader trends and influences in the context of their own life biographies, socialization, and the micro-social context of peer relations in the workplace (p6).

Recent research in the social sciences suggests that individual reflexivity (termed the "internal conversation" by Archer (2003, 2007)), driven by personal biography, context and personal concerns, provides useful information about how individuals engage with information and decision-making. Reflexivity is defined as the "regular exercise of the mental ability, shared by all normal people, to consider themselves in relation to their (social) contexts and vice versa (Archer, 2007, p4).

As Garcia-Ruiz and Rodriguez-Lluesma (2009) describe:

Human reflexivity becomes important as the linkage between concerns, projects and practices. We act in order to promote our concerns, and form projects to advance or to protect what we care about most. It is through our internal conversations that we reflexively define the courses of action conducive to the realization of our ultimate concerns in an appropriate modus vivendi [mode of living]. What people seek to do is reflexively defined by reference to the concerns they wish to realize. This means establishing practices, both satisfying to and sustainable by the subject, in an appropriate social environment (Archer 2007, p. 88). Hence, to understand the meaning of those practices it is necessary to grasp the life-projects in which they are embedded, as well as the ultimate concerns that underlie such projects (p. 223).

Archer (2010) asserts that most western social theorising has "regarded reflexivity as a more or less homogenous phenomenon" (2010, p5) which when applied in similar circumstances would lead to the same outcomes. This, of course, has induced analysts to search for the "silver bullet", the "critical success factors" which explain what most people will do most of the time - thus for broadband we are tempted to propose important identifiable supportive adoption factors such as price, speed, availability, ease of use and so on. These are identifiable external factors and are important considerations in the adoption decision. But such determinants need to be considered alongside the individual's internal reflexivity seen as an inner dialogue. Individuals always have the possibility to do otherwise than deterministic logic dictates.

Archer $(2000,2003,2007,2012)$ describes the importance of this mechanism, largely seen to be a consequence of the natal context, in explaining agents' life decisions. In a series of books she examines the role of reflexivity in today's society and proposes a number of dominant reflexive modes that can help to explain people's ultimate concerns and how these concerns impact their life choices. In particular, Archer (2000) explores the dynamics of reflexivity and places the "ultimate concerns" of the individual within "three orders of reality" which shape the outcomes of their "internal conversations": these are the natural, the practical and the social (p. 197). The natural world encompasses that which must be navigated to ensure physical well-being: avoiding hunger and stubbing your toe. The practical world demands that we take steps to get things done: to catch a bus or catch a deer, to use a monthly ticket or a bow and arrow. The social world provides normative directives and notions of self-worth and aspiration. The self (providing the "necessary anchorage" for the application of reflexivity) moves between these strata in making decisions or rationalising them away. It is this conception of individual agency that allows us to locate decisions to adopt broadband within a historical and dialectical context. Unlike a computer or decision tree that will identify, weight and process criteria immediately prior to the event, the application of reflexivity is a mode of deciding which unfolds from a preceding timeline in which physicality, emotion, active practice and reason have been engaged. 


\subsection{Modes of Reflexivity}

The notion of reflexivity in explaining the behaviours of agents and actors as developed by Archer is both simple and powerful (Mutch, 2007). It characterises individuals as variously adopting communicative, autonomous, meta and fractured modes depending on their personal concerns, projects and practices:

- The communicative reflexive inhabits a coherent, stable social world that is constantly reinforced by reiteration and external conversations with others, re-establishing and reinforcing the status quo.

- The autonomous reflexive is less reliant on others, more dependent on internal conversation and shuns predictability through this self-reliance and limited dependence on the "similars and familiars" that support and shape the conservatism of the communicative reflexive. They are primarily self-motivated, upwardly mobile, innovative, and not risk averse. They tolerate and flourish in contextual discontinuity and change.

- Meta reflexives are inward looking, contemplative and ask questions about the questions themselves: why do I think like this, what caused me to be this way? They are idealistic, support worthy causes or the disadvantaged, and can become socially seditious as they observe contradictions and historical conspiracies.

- $\quad$ Finally, fractured reflexives are passive agents who are unable to reflexively examine life's alternatives - they become frozen, unable to participate fully in reinforcing, changing or challenging the way of things - they are seen by Archer (2003) as societies "victims".

Archer suggests a relatively even division between each sector within today's society.

Emirbayer and Mische (1998) consider a more action-focused perspective and define three distinct capacities through which individuals engage with change: iterative, practical evaluative and projective. The iterative capacity is constrained to the continual reconstruction of the status quo, a highly conservative and static form of dealing with the world directed at reproduction of the past. The agent with practical evaluative capacity, whilst often conversational and therefore conservative, will adopt a technology if it fits existing purposes and structures in the present - a better kind of hammer, but still a hammer, so to speak. The projective capacity, focused on the future, and usually residing in autonomous reflexives, envisions new purposes and new structures for the realisation of aspirations. It is suggested that these three action-focused components of agency also play an important role in understanding the adoption decision by individuals.

Archer's communicative reflexive re-enacts external conversation with "similar and familiars" to develop their internal conversation, thus reinforcing conventionalism and "the familiar over the novel". As detailed in Table 1 below, we propose that the brand of non-use particular to the communicative would be disenfranchisement, displacement and perhaps disinterest. For the iterative old ways of doing would do just as well and little motivation is possible unless their similar and familiars adopt. Communicatives may tend to depend on other parties to fulfil their needs and may never completely adopt. The communicative reflexive would tend to adopt broadband if it was deemed to support iterative behaviours or if it were mandated in some way (for example for health services). Subsequent enactment would only ensue if trusted advisors from their relational group confirmed and supported their initial interest. This reflects Katz, Matsaganis and Ball-Rokeach's (2012) proposal to embed influence within local media and minority anchor groups as a means of helping the USA's National Broadband Program gain traction amongst ethnic groups in that country. Local media and anchor groups understand the context and life world of those groups and can frame the applications of Broadband in a way which makes sense to those participants.

The autonomous reflexive, with their dependence on their own reason and future orientation, would be practical or projective; they would be open to novel ideas or practical conceptions, 
providing they were in line with their instrumental purposes. In general they would be enthusiastic adopters of broadband and non-adopters would be considered as laggards - the attraction of the Internet for personal and social gain would ultimately be expected to lead to adoption. Selling broadband to the autonomous reflexive SME owner-managers, society's entrepreneurs, should not be difficult if they are familiar with Internet possibilities, but external factors such as speed, cost, and availability would be important in discouraging laggard behaviour. Perhaps in some cases they would need encouragement in self-efficacy and coaching to show how the broadband would directly improve utilitarian outcomes and their own life chances and business prospects.

In fact Archer (2007) suggests that the autonomous reflexive increasingly dominates today's globalized society: "Today, decreasing numbers of us live in the situation termed 'contextual continuity', which seems to be the necessary though not sufficient condition for the development of communicative reflexivity" (p. 320). Archer goes on to propose that the proportional reductions in communicative reflexives within today's society will lead to corresponding increases in autonomous reflexivity. As the situational logic of opportunity engendered by increasing globalization and contextual social discontinuity the autonomous reflexive will have increasing opportunities for personal advancement. Such argument is good news for broadband adoption, however as Dobson, Jackson and Gengatharen (2013) suggest, rural communities are perhaps more ensconced in a situational logic of protection, rather than opportunity. For rural communities the drift towards metropolitan cities, lower job opportunities and a desire to maintain the family encourages a focus on protection of opportunities and life chances in order to better fulfil their rural projects. For rural communities the predominant reflexivity mode would be the communicative reflexive who depends heavily on similars and familiars to help guide their life choices. This suggests a different approach is needed in rural communities - one focused on avoiding displacement and emphasizing the benefits for social groups.

It can be similarly argued that the meta-reflexive would increasingly be observed in rural regions as people move to the rural regions in order to avoid or address the incongruities of modern society. The meta-reflexive would be most open to the projective ideas and novel choices provided by broadband providing they were in line with their moral aims; their actions would be expected to be targeted at the greater good and could be ambitious and impractical in their social aims, perhaps even to their own detriment. Meta-reflexives may actively resist broadband for moral and altruistic reasons and may reflect a disenfranchisement in non-use. The ability of the Internet as a change agent would need to be emphasized and the social benefits achievable highlighted.

The hardest "nut to crack" would appear to be the fractured - their brand of non-use would largely be dis-interest and would perhaps be the most difficult to address. How can those disengaged from society as a whole be encouraged to adopt the social applications provided by broadband? The external factors suggested by traditional models would have little attraction for the fractured - broadband access would generally be used in public services such as libraries or government offices. Adoption of broadband would be a consequence of mandated requirements and would be limited and short term. Yet this sector of society is the most vulnerable to experiencing the disadvantages of non-use; the digital divide has serious implications in terms of accessing government services and information. Direct focused intervention would need to be introduced to individually introduce broadband and its benefits.

\subsection{Broadband adoption research models}

We have argued that the notion of reflexivity provides a powerful lens through which to explain the non-adoption of Broadband. In this section we discuss and evaluate other theories and approaches to understanding the uptake and use of technology in order to show where reflexivity offers a richer perspective, in particular for the conundrum of non-adoption.

Tsai and LaRose (2015) compare 5 models used by researchers to examine broadband adoption - the Technology Acceptance Model (TAM, Davis, 1986; Davis, Bagozzi and Warshaw, 1989), the Unified Theory of the Acceptance and Use of Technology (UTAUT, Venkatesh, Morris, 
Davis, and Davis, 2003), Diffusion of Innovations (DoI, Rogers, 2003), the Model of Adoption of Technology in Households (MATH, Brown and Venkatesh, 2005; Venkatesh and Brown, 2001), and Social Cognitive Theory (SCT, LaRose et al., 2007). They suggest that the first of these (DOI, TAM, UTAUT and MATH) work on similar foundations, each progressively extending previous models by adding particular variables.

Such development is useful and important, however, as Bagozzi (2007) suggests, the parsimony or simplicity of the TAM model is its major strength - the powerful core assumption being that intentions to use a technology influence adoption behaviour, and perceived usefulness (PU) and perceived ease of use (PEU) determine intentions to use. Nevertheless: "Parsimony has also been an Achilles' heel for TAM. It is unreasonable to expect that one model, and one so simple, would explain decisions and behavior fully across a wide range of technologies, adoption situations, and differences in decision making and decision makers. ...in favoring a simple model, researchers have overlooked essential determinants of decisions and action, and turned a blind eye to inherent limitations in TAM...Almost no research has deepened TAM in the sense of explaining PU and PEU, reconceptualizing existing variables in the model, or introducing new variables explaining how the existing variables produce the effects they do" (Baggozi p. 245).

In line with this suggestion we contend that existing models tend to inadequately represent the social reality of the agent and also have an unclear grounding in terms of representing the social and material context within which adoption occurs. We suggest that critical realism can provide a useful grounding for examining broadband adoption and non-adoption. In particular, we suggest that an individual's reflexivity is important in understanding how the existing identified factors will be less or more important for certain types of people and the personal projects they might be pursuing. The TAM model is a deterministic model that assumes causes inevitably lead to stated outcomes (Bagozzi 2007). There is no recognition of the mechanisms by which an agent may decide to do otherwise than expected. The TAM model tends to implicitly assume that non-adopters are "laggards" and will inevitably adopt if the conditions are right. Archer's reflexivity approach is useful in that it describes the mechanisms by which agents might fallibly respond to structures and actions. Individual reflexivity is an important mechanism for explanation of outcomes - in our case for explaining the surprising non-adoption in rural regions.

UTAUT builds on original DOI and TAM models to propose four key constructs: "performance expectancy, effort expectancy, social influence, and facilitating conditions that influence behavioural intention to use a technology and/or technology" (Venkatesh, Thong and Xu (2012, p. 159). The MATH model perhaps represents the most advanced of the models in that it builds on previous representations by suggesting that intention to adopt can be predicted by considering normative, attitudinal, and control beliefs: "Normative beliefs refer to other people's influence (including influence from friends and family, secondary (media) sources, and workplace referents) on an individual's behavior (Venkatesh \& Brown, 2001). Attitudinal beliefs include applications for personal use, children, work, fun, and status gains. Control beliefs entail fear of technological advances, fear of declining cost, cost of the product, perceived ease of use, and possession of the requisite knowledge to use the innovation".

Yet we suggest that such additional constructs seem arbitrary in their inclusion and are not reflected in a clear theoretical grounding. As Bagozzi (2007) suggests none of the models adequately reflect the group, cultural or social aspects of technology acceptance. Our paper argues that a useful model for representing the social role of people is critical realism - an approach fundamentally focused on the actions of agents within a pre-existing social environment. Such an approach seems more suitable in considering the adoption of a technology like broadband that has such wide social and personal implications.

The TAM is largely conceived as a model for the adoption of technology by individuals; where social influences are acknowledged they are represented as external constraints or enablers to the individual adoption decisions, as Bagozzi (2007 p. 247) suggests: "When so-called "social influence processes" have been introduced into TAM, the practice has been to treat social 
influence in the limited senses of either a constraint or force on the decision maker and perceived as originating from "other people whose opinions are important to me" (e.g., Venkatesh and Davis, 2000) or as an attempt to "enhance one's ... status in one's social system," such as a reference group (e.g., Moore and Benbasat, 1991, p. 195)". A model based around critical realism fundamentally reshapes the adoption argument in its acknowledgement that in such matters the individual cannot be separated from their social role, as Archer (1995, p. 1-2) suggests "...for what we are and what we do as social beings are also affected by the society in which we live and by our very efforts to transform it... We are simultaneously free and constrained and we also have some awareness of it. The former derives from the nature of social reality; the latter from human nature's reflexivity". Depending on the reflexivity of the individual concerned, reactions to impacting factors will be different. For example we would expect that for communicatives the identified variable "social influence" from the UTAUT model and observational learning from the SCT will have more relevance than for the autonomous or fractured. Similarly the autonomous may be more responsive to perceptions as to perceived usefulness in the original TAM model - their focus being selfdirected towards a focus on personal benefit.

LaRose et al (2007) propose the use of social cognitive theory (SCT) to examine adoption behaviours seeking to understand the inner reasoning leading one to accept or reject an innovation. The SCT approach proposes that perceived outcomes are formed through direct experience with one's own behaviour or through observation of the behaviour of others. The SCT grounding is used to propose additional causal factors termed enactive learning and observational learning. This approach is used to address the criticism that the diffusion paradigm often neglects the individual's capabilities and psychological factors and their role in technology acceptance or rejection. TAM and earlier models are said to instead focus more on the characteristics and qualities of the innovation rather than the important user perceptions: "That distinction is a crucial one in the present context, since the attributes of broadband Internet are more or less fixed while the perceptions of those attributes by consumers may still be malleable through promotional efforts" (p. 362).

SCT shares some elements with a critical realist approach in that both recognize the important role that cognition play in causal analysis. For both "reasons are causes", but critical realism provides a more developed foundation in that it also suggests an emphasis on pre-existing, perhaps non-recognized, non-ideational structures and mechanisms as well. As Johnson and Duberley (2000, p. 165) suggest:

While our knowledge of these structures is always interpretative, human agency draws upon extant structures as a condition of action. Moreover it is through human agency that social structures come about, are reproduced and transformed - regardless of our intentions or awareness that this is so. So while human behaviour in, for instance, organizations may often lie in and be caused by the inner interpretative reasoning of actors: for the critical realist there may be causes that are not recognized by, nor accessible to, those actors.

In particular, the work of Archer (2000) highlights the role of emotions and embodied "active practice" in guiding "inner conversations", reasoning and decisions. The richer model provided by critical realism can provide a better understanding of the non-adoption decision.

This distinction between adoption and non-adoption is important. As described above, adoption is a positive action whereas non-adoption may be a consequence of deliberate action or even disinterest. Forms of "non-use" will follow different causal chains and we argue will depend very much on the mode of reflexivity engaged by a person at the time.

\subsection{Modes of Reflexivity and Adoption Programs}

If avoidance of the adoption plateau is our goal, we propose that understanding the reflexive modes of various agents' and groups of agents has practical implications. Our characterisation of individual agency for example has consequences for the provision of information upon which to base decisions to adopt broadband. Although only a starting point, Table 1 presents 
the differentiated approaches that might be taken to encourage broadband adoption. It loosely proposes the application of aspects of the various TAM based and SCT models detailed above. The justification for so doing is that, whilst critical realism has fundamental issues with the underlying arguments of such models, they can provide suggestions as to likely tendencies of concerned agents.

Training programs to the general public, often communicative reflexives, must allow for patient and inclusive conversation which encourages re-evaluation of norms and collective assumptions to overcome their disinterest. Social norms influence attitudes to computermediated interaction but informed conversation can change them. Furthermore, information might be better delivered to cohesive social groups and in social environments to encourage ongoing conversation about broadband to take a positive and practical direction that gains momentum within a social group, rather than allowing the reinforcement of the status quo (which might be based upon a general ignorance of both their own life worlds and technology). Another strategy would be to embed technologically savvy agents of changes into community groups to conduct conversations about broadband in the language and context of the group. Whilst there is a palpable rural ideology, it is not clear how universal it is or indeed that everyone has bought into it. And yet as an "undiscussable" component of the rural social world, its presence can be felt in group defensiveness or rejection vis à vis Broadband and the Internet in general. The role of computer-mediated communication in enhancing existing practices and its possible practical applications may encourage adoption. Education or advertising about the benefits and scope of the Internet and broadband should be integrated into this fabric. It can be both discussed and demonstrated to strengthen and not diminish the country way of life.

Similarly, communicative reflexives are also responsible for and participate in small manufacturing, farming, medical services, country town historical societies or sporting clubs. The practical evaluative capacity of these agents must be engaged through understanding the social and business ontologies of their groups to identify and hook into the most salient aspects of those business and life worlds. These would lead to a picture of what is important in those groups and points of leverage for the NBN could be highlighted in education. Information provision, whether in advertising, training or brochures, should be as specific as possible to life worlds, providing specific and common scenarios and use-cases. Whilst it may be important for other reasons, non-specific advertising will probably not influence people in the decision to adopt. Again, embedding of domain experts or change agents who also understand the opportunities of broadband within such groups could help adjust attitudes to broadband to become more positive.

The autonomous reflexive seeks personal advancement and, if a non-adopter, will typically be a laggard, as this reflexive category otherwise tends to recognise and act upon the material benefits of new technologies. The cost-benefit equation is important here, and information provision should emphasise savings, efficiencies and functionality.

The meta reflexives on the other hand tend to be deliberate non-adopters, rejecting the mantra of function and transactional efficiency in favour of humanistic values. The social potential of the Internet to help others or enhance the lives of the excluded should thus be an area of focus.

This leaves us with the fractured, where the reflexive and material barriers and marginalisation will tend to be the greatest, where getting through the day might be an achievement. Reducing material obstacles by providing free access in public locations (such as libraries or social welfare agency offices) is a first strategy. Making the technology directly useful, easy to navigate and robust are very important, with co-location of empathetic, helpful staff to prevent easy discouragement. Table 1 summarises the differentiated approaches that might be taken to encourage broadband adoption. 


\begin{tabular}{|c|c|c|c|c|}
\hline $\begin{array}{c}\text { Agents' } \\
\text { Reflexive } \\
\text { Mode }\end{array}$ & $\begin{array}{l}\text { Type of non- } \\
\text { use }\end{array}$ & $\begin{array}{c}\text { Agents' } \\
\text { Reflexive } \\
\text { Capacity } \\
\end{array}$ & $\begin{array}{c}\text { Possible target } \\
\text { groups }\end{array}$ & Promotion Strategies \\
\hline Communicative & $\begin{array}{l}\text { Disenfranch- } \\
\text { isement, } \\
\text { Disinterest }\end{array}$ & Iterative & $\begin{array}{l}\text { Older rural people, } \\
\text { isolated communities, } \\
\text { some community } \\
\text { groups (historical } \\
\text { society, museum, } \\
\text { sport) }\end{array}$ & $\begin{array}{l}\text { Embedding empathetic specialists } \\
\text { within social groups, conducting } \\
\text { dialogue and sensitive } \\
\text { conversation in group contexts } \\
\text { Focus on Normative Beliefs } \\
\text { (MATH model) } \\
\text { Appreciating personal capacities } \\
\text { and self-determination. } \\
\text { Focus on group ontology } \\
\text { (community activity), specific use } \\
\text { cases and applications }\end{array}$ \\
\hline Communicative & $\begin{array}{l}\text { Disenfranch- } \\
\text { isement } \\
\text { Displacement }\end{array}$ & $\begin{array}{l}\text { Practical } \\
\text { Evaluative }\end{array}$ & $\begin{array}{l}\text { Farmers, small } \\
\text { businesses, artisans }\end{array}$ & $\begin{array}{l}\text { Focus on group ontology (business } \\
\text { activity), specific use cases and } \\
\text { applications } \\
\text { Focus on Normative and } \\
\text { Attitudinal beliefs (MATH) } \\
\text { Encourage enactive and } \\
\text { observational learning (SCT) }\end{array}$ \\
\hline Autonomous & Laggard & $\begin{array}{l}\text { Projective } \\
\text { and } \\
\text { practical } \\
\text { evaluative }\end{array}$ & $\begin{array}{l}\text { Managers, } \\
\text { community leaders, } \\
\text { innovators }\end{array}$ & $\begin{array}{l}\text { Enactive and observational } \\
\text { learning (SCT) } \\
\text { Improve external factors like } \\
\text { pricing, cost, availability etc, } \\
\text { Focus on Enactive learning } \\
\text { Address Attitudinal beliefs } \\
\end{array}$ \\
\hline Meta & $\begin{array}{l}\text { Active } \\
\text { Resistance } \\
\text { Disenchant- } \\
\text { ment }\end{array}$ & Projective & $\begin{array}{l}\text { NGOs, consultants, } \\
\text { volunteers }\end{array}$ & $\begin{array}{l}\text { Focus on Control Beliefs (MATH) } \\
\text { Emphasise social benefits and } \\
\text { opportunities }\end{array}$ \\
\hline Fractured & Disinterest & $\begin{array}{l}\text { Not } \\
\text { consistent }\end{array}$ & Marginalised groups & $\begin{array}{l}\text { Training in reflexivity to } \\
\text { understand personal capacities } \\
\text { and self-determination. } \\
\text { Emphasise non-exclusional } \\
\text { aspects of broadband (e.g. voice- } \\
\text { voice, applications requiring low } \\
\text { literacy) } \\
\text { Embedding empathetic specialists } \\
\text { within social groups, conducting } \\
\text { dialogue and sensitive } \\
\text { conversation in group contexts }\end{array}$ \\
\hline
\end{tabular}

Table 1: Summary of adoption strategies for modal groups

\section{Conclusion}

Activations to broadband are exceeding expectations for the NBN rollout, however, as discussed international experience suggests that adoption of the NBN will plateau as the rollout completes. As the rollout moves towards full coverage a focus must be made on nonadopters in order to achieve the social benefits promised by universal Internet adoption. We suggest that this universal adoption will be threatened as there will always be an element that will never adopt fixed or mobile broadband unless specifically targeted. Understanding the physical, practical, social and cultural characteristics of this group is an essential prerequisite to addressing inequities. We believe using Archer's model of self and reflexivity allows a rich analysis of adoption trajectories and has profound implications for future research. In rural regions in particular, we suggest that promotion of broadband needs to be cognisant of the dominant communicative reflexive element evident in the region - the dependence on "similars and familiars" to confirm or deny decisions, the family focus and lifestyle orientation of many inhabitants. The difficulties of enrolling the fractured are particularly challenging and will require significant investment in time and resources.

Generally, our analysis suggests that there is the opportunity for a more nuanced and sophisticated provision of knowledge and information to businesses and communities in rural 
and remote areas that will accelerate the uptake, application and innovative redesign of business and life worlds to exploit this landmark communications infrastructure. Accepting the more dominant role for the autonomous reflexive within metropolitan regions would allow a similar conclusion but the dominant message from our study is that no mode can be ignored - each mode needs to be recognized in advertising and promotions since all targets have their own particular issues and contextual concerns. In particular strategies need to be developed to target the fractured reflexive and to break through the evident disinterest and lack of connection.

Traditional Internet adoption models developed around the diffusion paradigm will be useful to develop strategies to convert non-adopters to adopters but the strategies need to focus on particular groups to be most effective. This paper suggests a social realist approach such as critical realism can provide useful grounding for examining the social, cultural and personal issues underlying non-adoption.

\section{References}

Archer, M. S. (1995). Realist Social Theory: The Morphogenetic Approach. Cambridge: Cambridge University Press.

Archer, M. S. (2000). Being human: The problem of agency. Cambridge University Press.

Archer, M. S. (2003). Structure, agency and the internal conversation. Cambridge University Press.

Archer, M. S. (2007). Making our way through the world: Human reflexivity and social mobility. Cambridge University Press.

Archer, M. S. (2010). Routine, reflexivity, and realism. Sociological Theory, 28(3), 272-303.

Archer, M. S. (2012). The reflexive imperative in late modernity. Cambridge University Press.

Bagozzi, R. P. (2007). The legacy of the technology acceptance model and a proposal for a paradigm shift. Journal of the Association for Information Systems, 8(4).

Broadband Commission. (2015). The state of Broadband 2015. Achieving Digital Inclusion for All.

Brown, S. A., and Venkatesh, V. (2005). Model of adoption of technology in households: A baseline model test and extension incorporating household life cycle. MIS Quarterly, 29, 399-426.

Cave, M., and Martin, I. (2010). Motives and means for public investment in nationwide next gneration networks. Telecommunications Policy, 34, 505-512.

Cradduck, L. (2016). Submission to the Productivity Commission Issues Paper June 2016Telecommunications Universal Service Obligation.

Davis, F. D. (1986). A technology acceptance model for empirically testing new end-user information systems: Theory and results. Doctoral dissertation. Sloan School of Management, Massachusetts Institute of Technology.

Davis, F. D., Bagozzi, R. P., and Warshaw, P. R. (1989). User acceptance of computer technology: A comparison of two theoretical models. Management Science, 35, 9821003 .

Dobson, P., Jackson, P., and Gengatharen, D. E. (2013). Explaining broadband adoption in rural Australia: Modes of reflexivity and the morphogenetic approach, MIS Quarterly, 37(3), 965-992.

Emirbayer, M., and Mische, A. 1998, What Is Agency?, American Journal of Sociology (103:4), pp 962-1023. 
Garcia-Ruiz, P. and Rodriguez-Lluesma, C. (2009), Reflexive consumers': a relational approach to consumption as a social practice, in Archer, M. S. (Ed.), Conversations about reflexivity. Routledge

Horrigan, J. B., and Duggan, M. (2015). Home Broadband 2015. Pew Research Center, December 21, 2015(4.)

Johnson, P., and Duberley, J. (2000). Understanding management research: An introduction to epistemology. Sage.

Katz, V. S., Matsaganis, M. D., and Ball-Rokeach, S. J. (2012). Ethnic media as partners for increasing broadband adoption and social inclusion. Journal of Information Policy, 2, 79-102.

Kontos, P. C., and Poland, B. D. (2009). Mapping new theoretical and methodological terrain for knowledge translation: contributions from critical realism and the arts. Implementation Science, 4(1), 1.

LaRose, R., Gregg, J. L., Strover, S., Straubhaar, J., and Carpenter, S. (2007). Closing the rural broadband gap: Promoting adoption of the Internet in rural America. Telecommunications Policy, 31(6), 359-373.

Moore, G.C. and I. Benbasat (1991), Development of an Instrument to Measure the Perceptions of Adopting an Information Technology Innovation, Information Systems Research, 2, 3 (September 1991), 192-222.

Mutch, A. (2007), Reflexivity and the Institutional Entrepreneur: A Historical Exploration, Organization Studies (28:7), pp 1123-1140.

NBN Co. (2016). NBN Weekly Progress Report as of 15 September 2016. from http://www.nbnco.com.au/corporate-information/about-nbn-co/corporateplan/weekly-progress-report.html

Perrin, A., and Duggan, M. (2015). Americans' internet access: 200o-2015. Pew Research Center, 26(6).

Rogers, E. M. (2003). Diffusion of innovations (5th ed.). New York: Free Press.

Satchell, C., and Dourish, P. (2009, November). Beyond the user: use and non-use in HCI. In Proceedings of the 21st Annual Conference of the Australian Computer-Human Interaction Special Interest Group: Design: Open 24/7 (pp. 9-16). ACM.

Stewart, J. (2007) Local Experts in the Domestication of Information and Communication Technologies, Information, Communication \& Society, 10:4, 547-569.

Tsai, H. Y. S., and LaRose, R. (2015). Broadband Internet adoption and utilization in the inner city: A comparison of competing theories. Computers in Human Behavior, 51, 344-355.

Venkatesh, V., and Davis, F. D. (2000). A theoretical extension of the technology acceptance model: Four longitudinal field studies. Management science, 46(2), 186-204.

Venkatesh, V., and Brown, S. A. (2001). A longitudinal investigation of personal computers in homes: Adoption determinants and emerging challenges. MIS Quarterly, 71-102.

Venkatesh, V., Morris, M. G., Davis, G. B., and Davis, F. D. (2003). User acceptance of information technology: Toward a unified view. MIS Quarterly, 27, 425-478.

Venkatesh, V., Thong, J. Y., \& Xu, X. (2012). Consumer acceptance and use of information technology: extending the unified theory of acceptance and use of technology.

Copyright: (C) 2017 Dobson \& Jackson. This is an open-access article distributed under the terms of the Creative Commons Attribution-NonCommercial 3.0 Australia License, which 
permits non-commercial use, distribution, and reproduction in any medium, provided the original author and AJIS are credited.

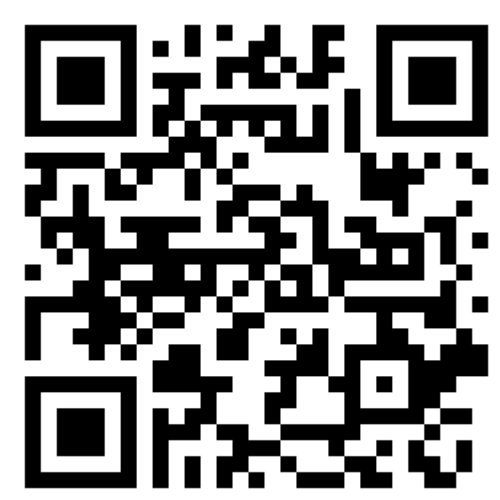

